\title{
The will to (de)liberate: Shaping governable citizens through cognitive behavioural programmes in school
}

\author{
Magnus Dahlstedt, Andreas Fejes and Elin Schönning
}

\section{Linköping University Post Print}

N.B.: When citing this work, cite the original article.

This is an electronic version of an article published in:

Magnus Dahlstedt, Andreas Fejes and Elin Schönning, The will to (de)liberate: Shaping governable citizens through cognitive behavioural programmes in school, 2011, Journal of education policy, (26), 3, 399-414.

Journal of education policy is available online at informaworldTM:

http://dx.doi.org/10.1080/02680939.2010.516841

Copyright: Taylor \& Francis

http://www.tandf.co.uk/journals/default.asp

Postprint available at: Linköping University Electronic Press

http://urn.kb.se/resolve?urn=urn:nbn:se:liu:diva-68953 


\title{
The will to (de)liberate: shaping governable citizens through cog- nitive behavioral programmes in school
}

\author{
Magnus Dahlstedt, Andreas Fejes, Elin Schönning \\ magnus.dahlstedt@liu.se, andreas.fejes@liu.se \\ Linköping University
}

Author Posting. (c) Taylor \& Francis, 2011.

This is the author's version of the work. It is posted here by permission of 'Copyright Holder'

for personal use, not for redistribution.

The definitive version was published in Journal of Education Policy, Volume 26 Issue 3, May 2011, 399-414.

doi:10.1080/02680939.2010.516841 (http://dx.doi.org/10.1080/02680939.2010.516841)

\begin{abstract}
Lately, a deliberative conception of democracy has gained influence in policy debates throughout Europe. Individuals are here seen to be fostered into responsible, mature - democratic - citizens by being involved in dialogue. In the 1990s, calls for "democratic education" intensified in Sweden. This article analyze two pedagogical models influenced by programmes developed in the US that have recently had a large impact in Swedish schools and elsewhere, Social and Emotional Training and Aggression Replacement Training, both teaching pupils the "art of democratic deliberation". By analyzing manuals and interviews with school staff, we find that both models are based on the idea that through constant dialogue, pupils develop a "democratic mentality". Referring to Foucault, this kind of dialogue can seen as a technology of confession, where pupils are encouraged to reflect upon themselves and their behaviour, abilities and qualities, as a way to change themselves and become democratic subjects.
\end{abstract}

Citizens are not born; they are made.

Barbara Cruikshank (1999, 3)

[O]ne cannot be but can only 'become' democratic.

Bülent Diken (2009, 154)

Citizenship education is not just a matter of learning the basic facts about the institutions and procedures of political life; it also involves acquiring a range of dispositions, virtues and loyalties that are immediately bound up with the practise of democratic citizenship.

Will Kymlicka (1999, 79)

The idea of dialogue as the very essence of democracy was presented with special emphasis during the 1990s among those representing a deliberative conception of democracy (Dryzek 1990; Fishkin 1991), an idea that has subsequently had an increasingly substantial impact within the European Union (Eriksen et al. 2004). Since the 1990s, a deliberative conception of democracy has had a particularly major impact in the area of educational policy, both within the EU (cf. Council of Europe 2000, 2006) and in Sweden (cf. Englund 2000; The Swedish National Agency for Education 2000), not least in relation to questions of democratic education and "citizenship education". In Sweden, more specifically, an ideal of deliberative democracy has permeated policy and one of the most crucial challenges faced in the work of strengthen democratic values is seen as that of creating a desire to engage in dialogue. Such desire for dialogue is taken up and mobilised in different school practices, for example, in the 
use of different therapeutic frameworks, models and working methods, ranging from working with the pupils in school to working with the parents through parental education (cf. Prins and Willson Toso 2008).

In this article we focus on two of these therapeutic frameworks, Social and Emotional Training, SET, and Aggression Replacement Training, ART, as a way to illustrate how dialogue is mobilised in school and how such mobilisation works in shaping deliberate subjects with certain characteristics. We believe that these frameworks, inspired by American sources and increasingly adopted by schools across Sweden and elsewhere (Feindler and Weisner 2006; Gundersen and Svartdal 2006), are typical of the times in which we live, and reflect a range of contemporary problem-conceptions and ideals, with a focus on the individual and her emotional and social deficiencies and merits. The programmes, through the use of dialogue, aims at educating the pupils in one way or another to become deliberative subjects, characterised by a well-developed "social competence".

Drawing on the later work of Foucault (2007) and his writing on governmentality and confession, we analyze how techniques of dialogue, within the frames of a deliberative conception of democracy, do confessional work that mobilise the pupils to make themselves visible for public and private scrutiny, at the same time as they are shaped into governing themselves. Empirically, we analyse interviews with staff from two different schools involved in SET and ART, as well as manuals related to these therapeutic frameworks. We see the teaching that is conducted within the framework of these two programmes as an expression of an "advanced liberal” governance (cf. Rose 1996), which primarily involves educating the students to become democratic citizens in accordance with the demands i.e. with the specific expectations and ideals, that prevail on the contemporary labour market.

\section{Analytical perspective}

Governmentality emerged during Foucault's (cf. 2005, 2007) later writings, a way to avoid too much emphasis on domination and power in his research. Thus, he shifted his focus to the interrelationship between the technologies of domination and the technologies of the self (Foucault 2003c). Governmentality focuses on the way the population and the individual citizen are being governed. The concept covers "the whole range of practices that constitute, define, organize, and instrumentalize the strategies that individuals in their freedom can use in dealing with each other" (Foucault 2003b, 41).

More specifically, what is analysed in a governmentality analysis are liberal rationalities of governing. Usually, we reason about liberalism and neo-liberalism in terms of political ideologies, political parties or as economic theories. However, liberalism can also refer to governmentality as it does here (as the broad mentality of how governing is problematised at a particular time). One could say that liberalism is a mode of governing (Dean 1999). Within such mode of governing, freedom is important. With the emergence of neo-liberalism, freedom has been reconceptualised. Neo-liberalism promotes a specific form of 'freedom' as a way of integrating the self-conduct of the governed into the practices of government. Freedom has become a resource for government, where the citizens' expression of their 'freedom' coincides with the political ambition to govern - 'freedom' has become both the instrument and the effect of governing (cf. Rose 1999).

Governing is conducted through different technologies, which aim to intensify the relation between institutional demands and institutionalised subjectivity. A technology does not have an essence, nor is it the outcome of a specific will or intention to govern (Fejes and Nicoll 2008). Rather it is an assemblage of elements that comes together tactically and aspires to shape specific subjectivities (Rose 19990). The technology of confession is one such assemblage that has become central to the exercise of power across the Western world, in part through processes of learning (Foucault 2007). As Foucault (2005) reminds us, confession has 
been part of different historical practices at least since Antiquity. However, the ways these practices operate has shifted. Previously, one had to renounce one's self so as to be able to take care of the self. Today, such renunciation of the self is not necessary. Instead, we construct knowledge about ourselves through verbalization of our self, and thereby our subjectivity is shaped and fostered.

A technology such as confession, operates through very specific techniques that target the subject and channel power through it. For example, in this paper we focus on dialogue as a technique within a wider confessional technology. Through this, the pupil becomes both object of knowledge (visible for calculation) and is made subject through a process whereby they come to know and act on themselves as particular kinds of citizens. Technologies depend upon such specific techniques in the shaping of subjectivities. Here there is no a priori self as an object or thing. Instead, the subject is decentred and analyzed as being shaped in specific ways in different historical practices (Foucault 2003b). Thus, instead of studying subjects as agents (a priori), the focus is on studying the specific historical practices, the technologies and techniques that make certain subjectivities emerge. In a decentring of the idea of the unified, coherent self, there is potential for a multiplicity of subjectivities, multiple and partial uptakes, constraints and elisions.

Based on the above, in a governmentality analysis, the interest is directed at analysing what subjectivity is constructed as desirable, how such subjectivity is being shaped (though what technologies and techniques) and what programmes of governing such constructions are part of (cf. Dean 1999; Fejes 2006; 2008; 2010).

\section{A therapeutic culture - SET and ART}

The gradual, increasingly powerful emphasis placed on working with the "democratic value base" has opened up schools to all kinds of moral-pedagogic techniques that involve teaching students the art of social intercourse and democratic deliberation, everything from "value exercises to develop the students' attitudes and democratic competence”, forum theatre and role play to a range of "varieties of moments of dialogue and reflection to begin or end the day or the week" (The Swedish National Agency for Education 2000, 44). Many of these pedagogic elements contain obvious similarities with therapeutic working models that have become increasingly widespread since the turn of the millennium in such fields are psychiatry, corrections and social work. At schools around Sweden, therapeutic models of various kinds - or parts of them - are used in the ongoing pedagogic work.

These models can be located within a wider framework, in which the "social problems" of young people are presented as an increasingly pressing and important problem for society at large. The social problems of the young are in turn linked to what is claimed to be a general increase in the level of "mental ill-health" among children and youth, and in particularly among what are referred to as youth at risk (cf. Riele 2006; Wishart et al. 2006). This image of worsening mental health among youth constitutes part of a general trend in society, whereby individuals are being increasingly intensely encouraged to work on themselves, to find their "real selves" and to become more aware of themselves, their limitations and abilities, to improve their self-confidence and to learn to manage their emotions. Frank Furedi (2004) refers to this social pattern as a "therapeutic culture", which is based on a psychological view of the individual and society.

One model that has had a particularly major impact on the contemporary therapeutic culture is CBT, or cognitive behavioural therapy. At the general level, CBT is about "changing how we think about our attitudes, goals and desires” (Andersson 2004, 397). The focus of this therapy is directed at the individual. CBT can be applied in different ways, but the method always involves a therapist employing a range of techniques to attempt to get the patients themselves to want to work on themselves and their inner lives, to improve their "social competence", to work with their feelings, develop their "moral reasoning" - both on their own and 
in collaboration with various people in their surroundings (see Andersson 2008; Hörnqvist 2007).

CBT is based on a traditional behaviourist view of people's behaviour and development. People's behavioural repertoire is viewed as a result of repeated and reinforced learning. The basic idea, against the background of this view, is that the therapist, by means of a series of interventions primarily directed at individuals who for various reasons are regarded as being at risk, actively supports a set of "desirable behaviours", while the individual's "undesirable behaviours" gradually abate or are "extinguished". The key to success, according to the CBT concept, is thus to continuously focus on possibilities, on the positive, and not on difficulties and problems - because doing the latter doesn't solve any problems, but rather locks the individual's thinking into negative patterns. Even though it is not always stated explicitly, however, the ideal - desirable patterns of values, emotions and behaviours - emerges first in the encounter with something problematic, undesirable or deviant.

Social and Emotional Training, SET, and Aggression Replacement Training, ART, are two CBT-based programs that are both inspired by American sources. The use of these - and similar - programmes has over recent years become widespread at schools in Sweden, as in many other countries (Feindler and Weisner 2006; Gundersen and Svartdal 2006). The idea of these programmes is to "protect" children and youths against various "risk factors" that are said to lead to "antisocial" and "undesirable behaviours". In both cases, such risk factors are viewed as being eliminable through the development of various types of "protective factors". One essential difference between SET and ART, however, is that the latter is first and foremost directed at students who are said to be at risk, i.e. students who are growing up in difficult social conditions, in environments that are "disadvantaged" economically, socially and in terms of status, whereas SET focuses as a rule on all students in school.

The special needs teacher and psychotherapist Birgitta Kimber, the inventor of SET, views what she refers to as "social and emotional competence" as one of the most important protective factors for combating the negative effects of risk factors such as "inconsistency in upbringing”, "peer problems", "bad company”, "not enjoying” school and living in a neighbourhood characterised by "unemployment [and] high crime" (Kimber 2004, 26). People who have developed a good level of "social and emotional competence," she argues, rarely seek "shallow pleasures but are rather attentive to their feelings so that these can provide assistance on the road to maturity and development" (p. 83). The lack of such competence, on the other hand, means "that you are unable to distinguish what feelings you have, and cannot therefore plan your life so as to make it as meaningful as possible" (ibid.). Kimber, Sandell and Bremberg $(2008,141)$ conclude that SET has some "small-to-medium effects on mental health and health-related behaviors" among pupils in school.

Similarly, the concept of ART is to change aggressive and antisocial behaviour patterns by offering more "social alternatives". According to the underlying concept of ART, youths' aggressive and antisocial behaviour patterns are primarily due to the fact that these youths lack "social-cognitive skills", the capacity to control their rage and "moral reasoning". Proceeding from this description of the problem, then, special "training" is proposed in interpersonal skills, anger management and moral reasoning. With regard to "interpersonal skills", the American psychologists Arnold P. Goldstein, John C. Glick and Barry Gibbs (1998) detail no less than fifty "skills" that youths should be "trained in", including listening, dialogue, convincing others, asking permission, being aware of their feelings, practicing self-control, rewarding themselves, coping with a failure, making a decision, setting about doing something, defining a goal. Taken together, the catalogue of skills depicts an image of an ideal, enterprising, aware and "socially competent" citizen and, in contrast to this ideal citizen, the image of a fundamentally problematic citizen, whose patterns of behaviour need to be changed in various respects. 
The implementation of each of the two programmes initiates a broad repertoire of tightly interwoven techniques whose objective is to stage students as democratic - in the sense of responsible, active and reflexive - subjects, in a variety of respects. However, the programmes do not constitute complete, ready-made "packages", but rather offer a wide range of different techniques from which the teachers put together a special set that they feel is appropriate specifically for them, for their school and for their pupils. As we shall see, however, dialogue is a consistent element in this flora of techniques.

\section{Empirical material and analysis}

In the following, we conduct a governmentality analysis of interviews conducted with staff who, in the course of their work, themselves teach the SET or ART programmes, or supervise other teachers who do so, as well as SET and ART manuals. The programme manuals analyzed are firstly, a series of ten SET manuals for teachers and students, respectively, Vital (Livsviktigt), developed by Birgitta Kimber (Kimber 2001a, 2001b), and secondly, two Swedish ART manuals, Tanke, handling, konsekvens (Brilje et al. 2006) and ART i skolan (Larsdotter 2009). The staff work at two schools in the compulsory education sector, Centralskolan and Nygårdskolan, located in a medium sized Swedish town. Susanne is a supervisor and Malin a teacher at Central; Lena is a supervisor and Anna a teacher at Nygård. Centralskolan is located in the centre of town, while Nygårdskolan lies in a stigmatised neighbourhood located a small distance away from the centre. Central has a broad catchment area and attracts students from varied social and cultural backgrounds. At Nygård, the majority of the students have an immigrant background and parents who are not used to studying. At Central, the teaching in ART is conducted in the form of a special resource group, a small group of students with a relatively large number of teachers. At Nygård, Life-skills (Livskunskap), the teaching that proceeds from the SET-programme, is an obligatory subject timetabled for one hour per week, from pre-school to year nine. During the interviews, the staff were asked to talk amongst other things about how they view their respective programme; the motives for working with these specific programmes; how the teaching is organised, which techniques are employed; what is taught; what types of consideration they are faced with in the context of this teaching.

Drawing on a governmentality perspective, our focus in the analysis has been on what is stated about SET and ART within interviews and manuals, what subjects are positioned as desirable, and how the technology of confession and its associated technique of dialogue operate in shaping desirable subjects (cf. Dean 1999). By reading interview transcripts and text manuals concerning ART and SET, and conducting a thematic analysis drawing on these questions, three central pedagogical techniques that are staged through the teaching in the SET and ART programmes respectively at the two schools have been identified; these techniques comprise motivating, acknowledging, and calculating and they all mobilise dialogue as a way to shape and foster subjectivity.

\section{"You have to want to change" - the art of motivating}

According to the underlying concept of both SET and ART, students are active not passive; or rather all students can at least become active if given the right kind of training. This is a view that runs through interviews with teachers as well as manuals for both programmes (Kimber 2001a, 2001b; Larsdotter 2009), like some kind of organising idea. Through the implementation of a range of techniques, students are expected to gradually develop some kind of desire to become active and "change themselves". The focus for the teaching is directed at the students' independence and self-reliance, their motivation and their desire.

When the teachers talk about the working methods they use in their teaching, they all express an ambition to teach the students to take responsibility for their actions in a series of 
everyday situations involving various kinds of moral and ethical issues. In the interviews, in addition to the pure transference of knowledge, education to responsibility or responsibilisation emerges as one of the more important tasks of schools, particularly in the context of the teaching that is conducted within the framework of SET and ART. According to Anna, for example, one of the most important goals of this education to responsibility is that of bringing about a change in the students' thinking.

Responsibility, you have to assume responsibility of course, always. So that's like kind of... actually it's, you know, a very fundamental thing. I mean, if you go to a lesson and you are assuming responsibility, then you have to make sure that you take the things you need with you, you have to get there on time and you have to keep track of homework and what tests you have to take. It's about responsibility, for the kids right now, and then to build further on this responsibility itself.

The teachers - like the policy documents - emphasise the students' motivation and desire as preconditions for the possibility of producing desirable change. One of the individual teacher's central tasks in this context involves using various means to get the students to feel that they are participating in the teaching of their own free will. It should "feel like fun and feel motivating to come to the classes", Susanne notes, and emphasises that the desire to change must "come from the students themselves", a point that is also repeated in a variety of ways in the manuals for both SET and ART studied (Kimber 2001a, 2001b; Brilje et al. 2006; Larsdotter 2009). "You have to want to change”, Susanne continues, "otherwise it isn't possible and you have to understand and feel that you can benefit from it". According to Susanne, the significance of motivating the students to participate of their own free will is particularly crucial in the initial phase of the ART-teaching, where it is important to "present it in such a way that the student feels stimulated to participate”.

One important element in the teaching of both SET and ART involves dialogue on a wide range of issues, in which the students are at the same time expected to act both as confessors and to confess their sins, a kind of conduct of conduct (Foucault 2007). Through dialogue with others, the idea is that the students will learn to reason with themselves and with others, to formulate their experiences and points of view, to respect others' points of view and, in dialogue with others, to both revise and stand up for their own. By means of this process, the students are "activated" at the same time as their opinions, desires and fears are made visible, and are in turn related to the prevailing ideals that operate in school practice. In this way, active subjects are formed who govern both themselves and others in relation to prevailing ideals. In line with this idea of getting students to learn to reason, Birgitta Kimber $(2004,33)$ also emphasises that SET educates students to democracy in a number of different respects. "Solving problems can be very useful in connection with democratic education, for example during class council periods. Other elements that are important to democratic education are listening, waiting one's turn, having value exercises that train the students to see and appreciate that we are all both the same and different”. In addition to the act of confession itself, the working method reflects a deliberative concept as the point of departure - dialogue between people is the life-blood of democracy.

The democratic dilemma in this context, however, is that certain students may feel uncomfortable about talking in front of others at all. According to these programmes, the desire not to talk must also be respected. As a result of this, students also always have the opportunity of saying "pass", i.e. of choosing not to answer or participate in a discussion. "You don't force anything on anyone", explains Anna. "I mean, we are so different as individuals. Some people think it's really tough just to talk in front of a group and things like that. And it's also something that you have to practice of course". In other words, the act of confession is not some- 
thing that is coerced, but rather something that should take place in the name of freedom. Subjectivity is here elicited and fostered rather than determined.

At the same time as the teachers strongly emphasise the principle of the students' voluntary participation in the various exercises that are staged, a hope that the students - in the end - will choose to participate in the teaching, by themselves realising the benefits of participation. Anna speaks, for example, about how the teacher cannot force students to participate in specific exercises, because as individuals everyone is different, but then in her next sentence she nonetheless emphasises the importance of all students participating in the exercises and learning the same things. The voluntary ideal is in other words strongly contradictory. At the same time as it is viewed as valuable for all students to actively participate in the teaching, it is also viewed as important that the students themselves perceive their participation as voluntary. According to the teachers, there is otherwise an imminent risk of individual students perceiving the teaching as a violation of their integrity. In this the teacher is faced with a complex dilemma: How to get the individual students to themselves want to participate, in a situation where they don't have to participate? Thus motivation and desire not only emerge as a condition for steering the students in the "desirable" direction, but also, to the same extent, as a result of this steering, i.e. as something that constantly needs to be maintained and worked on. With this ambivalence, we find ourselves in what Uljens (2002) labels the pedagogic paradox, where education is viewed as a provocation to self-reflection where the individual is to transcend her own capacity by her own activity. But to be able to reach beyond this, the individual must already be conceived as autonomous and self-reflecting. In other words, the pedagogic process appears to require the pre-existence of that which it is trying to create.

\section{“Do you think you deserve a heart?" - the art of acknowledgement}

One of the fundamental principles associated with SET and ART, as with a range of other CBT-oriented models, is that effective teaching should focus primarily on the positive rather than the negative, on possibilities rather than problems. This message is underlined strongly both in our interviews and in programme manuals (cf. Kimber 2001b; Brilje et al. 2006). All informants emphasised that teachers should consistently acknowledge - praise, encourage and reinforce - the behaviours they perceive as positive rather than punishing various types of transgressions and "undesirable" behaviours. This is due to the fact that all forms of attention tend to spread, either in negative or in positive circles. One way of strengthening desirable behaviours may be to provide rewards, both individually and in the group.

All informants speak of the value of using different systems of rewards for the purposes of acknowledgement in their teaching. Amongst other things, Malin describes how she and other ART teachers at her school consistently apply a rewards system in order to improve the motivation and propensity of the students to participate in the teaching. However, the rewards system does not only function as a way of working on the students' motivation, but also as a means of staging and maintaining the ideals and rules associated with the teaching. In the ART-group, the teachers use heart-stickers to acknowledge desirable behaviours. Students who "do well" are acknowledged by means of symbolic hearts, while those who do not do so well are left without. When the students have collected a sufficient number of hearts, they can choose the reward they desire. Similar working methods and structures are employed in many other schools, including schools that do not explicitly work according to the methods of the SET and ART programmes. At the end of every lesson, says Malin, the students are themselves asked whether they feel that they deserve a heart, i.e. to say whether or not they feel they have done well.

We work with the hearts of course, and if you do well you get a heart. And then it's about that you... do well in lessons. And then it's we teachers who set the limits for... I mean doing well is a bit... you know, who does well and who doesn't do well? But it's we 
teachers who decide, and as a rule every lesson finishes with a round of the class where we ask: "Do you think you deserve a heart for this lesson, why and why not?" But they know what it's about. [...] It's about sitting still and working. Then you get a heart. And if you get a hundred hearts you can choose between a cinema ticket and a massage.

Thus it is essentially the teachers who decide which students have and which have not done well, on the basis of their assessments of what is right and wrong, desirable and undesirable. The situation of negotiation described by Malin could thereby be viewed as a way of getting the students to feel they are participants in the decision-making process, i.e. of involving them in the process so that that they are motivated to participate in the lessons. This in spite of the fact that - in the final analysis - it is the teachers who decide which students have done enough to merit a heart - and which have not.

What is really central in the process at the end of each lesson, in which the students are involved in defining whether or not they deserve a heart, is not the negotiation itself however. The negotiation process can in itself be viewed as a kind of confession, a process whereby the students are encouraged to reflect upon themselves and their behaviour, their abilities and qualities, and in certain cases to define their own inadequacy or deviance. The confession, both for oneself and in the face of one's surroundings, functions here as a deliberative pedagogic technique focused on also involving the students in the teachers' work of continuously scrutinising/evaluating the students' performance and acknowledging those behaviours that are regarded as desirable.

In one sense, the logic seems quite contradictory to the idea of focusing attention first and foremost on that which is viewed as positive and desirable, and not on inadequacies and problems, since the negotiation also opens the way for negative assessments, i.e. that individual students do not live up to the requirements for good conduct. In the context of the negotiation, however, it is up to the students - not the teacher - to assess whether or not they live up to these requirements. If a student assesses that he or she for some reason or other has not done so, then this assessment is the student's - not the teacher's - even if the students may have come to regard themselves from the perspective of the teacher's definition of good conduct. In this way, the confession also functions as a kind of technology of the self, whereby the students are made to reflect upon themselves, individually and in dialogue with others, as a means of changing themselves in the direction of that which has been defined as the ideal condition. The ability to continuously reflect upon oneself in relation to the surrounding world, and of sharing these reflections in dialogue with others, is one of the most central characteristics of the democratic, lifelong learning subject that the teaching has the objective of fostering. One particularly crucial question here is that of the capacity to calculate, i.e. to reflect upon the possible consequences of one's behaviour and how it may be perceived in various situations.

\section{"The rewards may come later" - the art of calculating}

Both SET and ART explicate the importance of focusing on possibilities rather than limitations, not least by reference to the fact that a focus of this kind turns pupils into active subjects rather than passive objects or victims. "It's very important to concentrate on what actually works", notes Birgitta Kimber (2004, 41), for example, "instead of focusing energy on what doesn't work". "In this way you create possibilities, instead of becoming a victim”. For the teacher, argues Kimber, it is important in this context to show that he or she trusts the students. One way of showing trust, she continues, is to give the students options, to teach them that they always have a choice, whether they choose to make an active choice or not: "The students are used to either doing as they are told or not doing anything at all. If they are instead given the opportunity to choose, they come to participate more and can make their own decisions. In this way you teach them to assume responsibility and they become more eager to 
involve themselves in their schoolwork” (p. 60). By learning that they always have a choice, and that every choice has different consequences, which they themselves have to deal with, the students simultaneously learn that they are not passive victims, but instead that it is always they themselves who govern the paths they take through life.

All informants emphasise the capacity to make choices and to reflect carefully over the possible consequences of choosing the one thing or the other, as one of the greatest challenges in the context of the teaching. The students are regarded as needing to learn to calculate, i.e. to see and manage their lives as a more or less infinite series of choices, both large and small. In this regard, the informants spoke of the students needing to be made aware of the fact that they can always act to change the world. Nobody is a victim of circumstances. It is important to get the students to both see and accept the consequences of their own actions, to assume responsibility themselves and not pass responsibility on to others. Anna describes the life-skills classes in precisely these terms. For her "life-skills" is about teaching the students the things they need to know right here and now. In a longer-term perspective, "life-skills" is about teaching the students to take responsibility for their lives as adults. Here Anna particularly emphasises the importance of learning to take responsibility for one's own actions and of seeing them in relation to a larger context. One way of teaching the students to take responsibility may be to draw parallels with, and take examples from, everyday situations as a means of showing the students the importance of thinking for themselves in a range of different situations.

When you get out into the real world, you might park the car in the wrong place, and that's expensive. And just at the minute it doesn't cost anything, but the cost comes when you make that particular mistake. And then it's good if you only do it once. It's no fun having to pay fines several times. So we use those kinds of examples.

Anna emphasises that it is important that the students learn to assume responsibility while they are still young so that they take these lessons with them when they get older and don't "repeat the same mistake several times". In the same spirit, Malin emphasises the importance in the ART-teaching of getting the students to realise "that everything has consequences, so they must think before they do anything".

Several of the examples provided by the informants of how to clarify the idea of thinking about consequences relate to the students' future working lives in one way or another. When Malin speaks of how the students need to learn to be well-prepared when they take on various tasks, for example, she chooses to exemplify by referring to a job interview: "The first time they go to a job interview, what should they think about? Do you have to think it through, or do you just have to turn up? Or is it good to be prepared?” According to Malin, the ARTstudents have a substantial need to learn to reflect on the consequences of different behaviours, not only in order to cope well in school and in their lives today, but also to be able to cope with the many and difficult challenges of adult life.

According to this view, the students' behaviour is something that follows them and affects their possibilities of being "accepted" in later phases of their lives. It is the teachers' task to constantly emphasise the students' responsibility for calculating the risks and consequences of various actions on a day to day basis, even where these consequences will not become visible until much later. Malin describes the teaching in the ART-group as a process in which the students gradually learn to use the "right" strategies in order to get attention. From Malin's perspective the "wrong" strategies are those which are "too" noticeable and which attract too much external attention. According to Malin, students need to plan and think about their behaviour in a goal-focused manner. 
Do you want to be seen, and in what way do you want to be seen? And for what do you want to be given attention? [...] And how you should act in the corridor to avoid being singled out? Because these students are the kind that feel stigmatised, they feel "Yes, but we're always the ones that get the crap for whatever happens in the corridor, and that kind of thing." It has to do with their past, of course. And then we've explained that unfortunately it's often the case that if you've done something stupid before, then it stays with you for a long time. That's why it's important now when they come into further education that they think first... that everything they do produces consequences.

Here we can also see that very special significance is ascribed to the fact that ART is focused on a specific category of students. Malin describes the ART-students as incapable of behaving in accordance with the ideals and "social codes" that prevail in different social situations. The image of the ART-students is here chiselled out in relation to an imagined normality. At one point during the interview, the picture of the students is presented in contrast to Malin herself, as a teacher and an adult. By contrast with the students, Malin says that she herself "automatically" knows how "one” should dress and behave in different situations.

This is the kind of thing that teachers do automatically, it's not something that I have to focus any energy on, since I automatically know: "Yes, but if I'm going there then one wears this type of clothes, one behaves like this.” But these [students], they don't know this. They have no idea. They could just as happily turn up to a job interview just as they were. We did a lot of training on this before they had their work placements. What to do when you phone for the first time, how you present yourself, because it's not something they carry with them, or know and it's not something they practice at home.

One important question is that of how the teachers can and should deal with the students' various dreams and expectations of the future. According to Malin, she and her colleagues work consciously to train the students to think in a goal-focused manner about their dreams about working life. She emphasises the necessity of getting the students to learn to first define concrete goals for what they want and then to try to focus on achieving these goals by acting in accordance with the expectations and demands that can be expected to exist at future workplaces. During lessons, thinking about consequences is staged amongst other things in the following way: Each student starts by talking about what they want to be. Thereafter the teachers ask questions on the basis of their experience of each individual student and how s/he usually reacts in different situations. The students are thus faced with different scenarios that they might hypothetically find themselves in. Malin argues that there may be a pedagogic point to pushing individual scenarios to their limits in order to get the students to really understand the importance of thinking carefully about their behaviour here and now.

If we put it like this: One of them wants to become an actor, that's the goal, that's the job! Yes, but how do you achieve that? [...] Yes, but if you want to be that, then maybe you have to fix this and then there's a lot of people who will be watching when you stand on the stage, can you cope with that? [...] One of them wants to have a garage of his own. Okay, then we look at that. Okay, then you have to think that if you get into an argument with someone now, then it might be someone who will be buying your services later on [...] As far as possible, we try to cover everything so that they try to think about their behaviour now, that it has consequences far into the future...

Lena emphasises the importance of the students learning to set concrete goals for their future working lives in similar terms. She describes how the teaching in life-skills often focuses on setting realistic goals so that the students are then able to attempt constructively to achieve 
these goals. It is important, Lena argues, that the students learn that "the rewards may come later”.

In life-skills you also work with things that are fairly concrete. Setting realistic goals, for example. And then working constructively to achieve those goals. When you're small, for example, you get some kind of immediate feedback or acknowledgement. You have to practice that the rewards may come a little later [...] It is probably quite okay to want to be an astronaut, although [laughs] it may be good to have a few smaller goals along the way.

In other words, SET and ART mobilise reflection as a technique whereby individuals are encouraged to reflect and evaluate their own abilities and their conduct in relation to future scenarios. By confessing their defects and faulty choices to themselves, "better" citizens are to be moulded. Such citizens are themselves made responsible for the setting and realisation of goals that are in line with what a "normal" and "good" citizen consists in. Even if schools, and the pedagogic techniques that are mobilised in schools, create opportunities for the students to become the citizens that are prescribed, it is in the final analysis up to the individual to make use of the opportunities that are provided. As has already been mentioned, this assumes both that the individual is active a priori, and at the same time that this is also the effect of participating in the schoolwork.

\section{Schooling for democratic citizenship}

Given that the role of schools is to educate future citizens, what we can see here is the prevailing ideal of our time with regard to democracy and citizenship, how rights are balanced against obligations, which civic qualities, capacities or characteristics are viewed as desirable and as undesirable and in need of retraining. The increasingly marked presence of programmes such as SET and ART in the Swedish educational landscape is in many respects a sign of the times. These programmes reflect a series of contemporary perceived problems and ideals. Even though SET and ART were developed in different contexts (Sweden and the USA respectively) and have a somewhat different focus (SET is directed at all students, while ART is primarily focused on at risk students), they are in many respects very similar. This can be seen from both interviews conducted with staff working with the programmes and from programme manuals. In both interviews and manuals, we see what is essentially a common view of the problem, the same type of working methods, and similar views of what constitutes an ideal democratic citizenship.

Both programmes proceed from a therapeutic framework based on developmental psychology and its assumptions about human development, autonomy and individualism. The central focus is the specific individual's inner life. In accordance with the foundational therapeutic idea, several of the challenges and problems faced by society are defined in terms of mental ill-health, deficient "social competence" and a deficient capacity to manage one's emotions (Bartholdsson 2007; Furedi 2004). In all essential respects, the individual is viewed as both the problem and the solution. Problems such as disturbances and disorder, school difficulties and unemployment are largely understood as the result of a set of "risk factors", and then particularly individual deficiencies or incompetence of various kinds, rather than as a result of societal conditions, such as family circumstances, poverty, structural inequalities and social relations. The recurrent message in both interviews and programme manuals (cf. Larsdotter 2009) is that the students who participate in the teaching both can and should "change themselves", in the sense of working on themselves. Everyone can achieve success in life. Even those who are at risk have potential. All they need is a little help along the way, to find and refine this potential. In other words, in order to get the students to change externally (how they dress, relate to people, behave), what is needed is to work on them internally (their motivation, drive, desire). 
Our analysis has pointed to three different pedagogical techniques that all mobilise dialogue as a way to shape and foster desirable subjects: the art of motivating, the art of acknowledging and the art of calculating. On a general level, all these techniques shape the same kind of subject - an active, democratic and responsible subject - which is also the objective of the teaching of SET and ART. A democratic subject is one who can live a productive and well-behaved life without any aggressive or ill-placed behaviour. Such a subject is contrasted with how these students are positioned today: as deviant in certain situations, antisocial or undesirable in some other respect. As a way of shaping such desirable citizens, the CBT programmes do not work through coercive techniques that determine action and behaviour. Rather, they mobilise techniques that shape, foster and elicit subjectivity.

This is, for example, done by doing work to motivate the students to take responsibility for their studies and thus training to become responsible citizens. As in the deliberative conception of democracy that has recently had a major impact, for instance, in Swedish education policy, dialogue is seen as an important element in the work of democratic schooling. Through dialogue, in practices such as class council periods or in value exercises, pupils are encouraged to express their opinions about ethical and practical issues at school. However, pupils should not be forced to participate, as this would be counter to the democratic ambition of the programmes. Instead, the students need to be made to feel that participation is voluntary. Thus, motivation to participate is both a prerequisite and an effect of participation. Dialogue is also mobilised when the teachers acknowledge the students' good behaviour. The students are themselves asked if they think they deserve a heart representing good conduct. Thus, they are invited to participate in a dialogue, and through this they need to scrutinize themselves and their behaviours and make the result of such scrutiny visible to others. By doing so, they turn themselves into an object to be compared, inspected and evaluated in relation to what is deemed desirable. This is both a process of objectification and subjectification through which the student comes to know who she/he is (Foucault 20005). Similar processes take place when students are invited to participate in a dialogue about what they want in the future. Here, the students are invited to share with others their inner desires in life, and by doing so they need to scrutinize themselves in terms of conduct and abilities. These are then compared to those presented by the teacher as necessary to get to where they want to go. In this dialogue, students are trained to calculate risks and consequences of different kinds of actions in certain situations. Thus, they are invited to be active and responsible in relation to their desires, i.e. a modification of behaviours is expected as the outcome of such dialogue.

The above summary points to how confession, through dialogue, is a central part of CBT programmes that aim to modify and shape conduct. However, this is not forced upon the students nor are they coerced. Rather, they are invited to act on the basis of their freedom. We thus have what Foucault (2007) calls the conduct of conduct, where students are conducting their own behaviour at the same time as they conduct the behaviours of others. By regulating themselves, changing their selves into what is deemed desirable they are reproducing the ideal of good behaviour, and thereby participating in regulating the conduct of others. This can be related to what Nikolas Rose (1999) calls an advanced liberal governance that essentially consists of educating students to become democratic citizens in line with the demands, the specific expectations and ideals, of the contemporary labour market. Responsible, flexible and active subjects are highly valued in today's labour market (Dovemark 2007; Österlind 1998) and such ideals are reproduced in the CBT programmes in school. Here, through an advanced liberal rationality of governing, power works through the freedom of the students, with the effect of shaping subjectivity. There is at the same time both an incentive and an offer to act and behave in a certain way, and an opportunity for the students to choose to accept or decline such an offer. Either way, the students are using their freedom, thus they are at the same time constituted as free and autonomous subjects, which is the goal of an advanced liberal rationality (cf. Rose 1999). However, those who chose to decline the offer are categorized as the 
"others", the unwanted and the undesired citizen who will be in need of even further behavioural modification programmes.

Capacity for dialogue constitutes a key civic competence as construed within these programmes. Through dialogue the student is assumed to acquire the "characteristics" of responsibility, flexibility and autonomy. For it to be possible to educate students to become democratic citizens, it is necessary however to create a desire to engage in dialogue. The therapylike teaching conducted in SET and ART thereby provides, in its constant endeavour to motivate the students and increase their awareness, to strengthen their self-confidence and to deepen their insights, an expression for a paradoxical will to empower (Cruikshank 1999). The teaching may well be motivated by the best of intentions (to liberate, activate, strengthen and motivate students to take responsibility for themselves), but it nevertheless constitutes an intricate form of governance, a form of democratic governmentality, based on normalising certain ways of being and thinking as a citizen and presenting these as self-evidently normal and desirable, while these are simultaneously distinguished from that which is regarded as abnormal, defective and undesirable - activity is contrasted with passivity, the civilised with the primitive (Andersson 2004). This type of individualisation of defects and incapacities, like the responsibility of the individual, is here made possible by knowledge from the field of developmental psychology at the same time as such knowledge cannot be separated from the pedagogic techniques that are created in order to normalise and mould the subject (see Walkerdine 1984). In other words ART and SET are both a product of developmental psychology and at the same time they produce such knowledge. Through the mobilisation of a range of confessional practices, in which dialogue constitutes and important element, the students are worked on in relation to the ideal of the good citizen. Here too the point of departure is the individual and his/her autonomy, which constitute the means by which the ideal relating to what is desirable and undesirable is reproduced.

\section{Acknowledgements}

This research was made possible by a grant from the Swedish Research Council.

\section{References}

Andersson, R. 2004. Behandlingstankens återkomst. Nordisk Tidsskrift for Kriminalvidenskab 91: 384-403.

Andersson, K. 2008. Talking violence, constructing identity. Linköping: Department for thematic studies, Linköping University.

Bartholdsson, Å. 2007. Med facit i hand. Stockholm: Department of Social Anthropology, Stockholm University.

Brilje, I., L. Strandberg, and D. Kliba. 2006. Tanke, handling, konsekvens. Malmö: Ungdomsalternativet/UngArt.

Burchell, G. 1996. Liberal government and techniques of the self. In Foucault and Political reason: Liberalism, neo-liberalism and rationalities of government, eds. A. Barry, M. Osborne and N. Rose., 19-36. Chicago: The University of Chicago Press.

Council of Europe. 2000. Presidency conclusions. Lisbon, 23-24 March. Strasbourg: Council of Europe.

Council of Europe. 2006. Higher education and democratic culture. Strasbourg: Council of Europe.

Cruikshank, B. 1999. The will to empower. Ithaca: Cornell University Press.

Diken, B. 2009. Nihilism. London: Routledge.

Dovemark, M. 2007. Ansvar - hur lätt är det? Lund: Studentlitteratur.

Dryzek, J. 1990. Discursive democracy. Cambridge: Cambridge University Press. 
Englund, T. 2000. Deliberativa samtal som värdegrund. Stockholm: The Swedish National Agency for Education.

Eriksen, E.O., J.E. Fossum, and A.J. Menéndez, eds. 2004. Developing a constitution for Europe. London: Routledge.

Feindler, E.L., and S. Weisner. 2006. Youth anger management treatments for school violence prevention. In The handbook of school violence and school safety, eds. S.H. Jimerson and M.J. Furlong. Mahwah: Lawrence Erlbaum Associate.

Fejes, A 2006. The Planetspeak Discourse of Lifelong Learning in Sweden: what is an educable adult? Journal of Education Policy 6: 697-716.

Fejes, A. 2008. To be ones' own confessor: Educational Guidance and Governmentality. British Journal of Sociology of Education, 29: 653-664.

Fejes, A. 2010. Confession, in-service training and reflective practices. British Educational Research Journal, First published on: 21 July (iFirst)

Fejes A., and Nicoll, K. eds. 2008. Foucault and lifelong learning: Governing the subject. London: Routledge.

Fishkin, J.S. 1991. Democracy and deliberation. New Haven: Yale University Press.

Foucault, M. 2003a. The subject and power. In The essential Foucault: Selections from the essential works of Foucault 1954-1984, eds. P. Rabinow and N. Rose., 126-144. New York: The new press.

Foucault, M. 2003b. The ethics of the concern of the self. In The essential Foucault: Selections from the essential works of Foucault 1954-1984, eds. P. Rabinow and N. Rose., 2542. New York: The new press.

Foucault, M. 2003c. Technologies of the self. In The essential Foucault: Selections from the essential works of Foucault 1954-1984, eds. P. Rabinow and N. Rose., 145-169. New York: The new press.

Foucault, M. 2005. The hermeneutics of the subject: Lectures at Collège de France 19811982. New York: Palgrave-Macmillan.

Foucault, M. 2007. Security, territory, population: Lectures at the Collège de France 19771978. Houndmills: Palgrave MacMillan.

Furedi, F. 2004. Therapy culture. London: Routledge.

Goldstein, A. P., B. Glick, and J.C. Gibbs. 1998. Aggression replacement training. Champaign: Research Press.

Gundersen, K., and F. Svartdal. 2006. Aggression replacement training in Norway. Scandinavian Journal of Educational Research 50: 63-81.

Hultqvist, K., and K. Petersson, eds. 1995. Foucault: Namnet på en modern vetenskaplig och filosofisk problematik. Stockholm: HLS Förlag.

Hörnqvist, M. 2007. The organised nature of power. Stockholm: Department of Criminology, Stockholm University.

Jacobsson, K., and Å. Vifell. 2007. Deliberative transnationalism? In Economic government of the EU, eds. I. Linsenmann, Ing C.O. Meyer, and W.T. Wessels. Basingstoke: Palgrave Macmillan.

Kimber, B. 2001a. Livsviktigt: Social och emotionell träning - SET. 1-10, Elevbok. Solna: Ekelunds.

Kimber, B. 2001b. Livsviktigt: Social och emotionell träning - SET. 1-10, Lärarhandledning. Solna: Ekelunds.

Kimber, B. 2004. Att främja barns och ungdomars utveckling av social och emotionell kompetens. Solna: Ekelunds.

Kimber, B., R. Sandell, and B. Bremberg. 2008. Social emotional training in Swedish classrooms for the promotion of mental health: results from an effectiveness study in Sweden. Health Promotion International 23: 134-143. 
Kymlicka, W. 1999. Education for Citizenship. In Education and Morality, eds. J.M. Halstead and T.H. McLaughlin. London: Routledge.

Larsdotter, S. 2009. ART i skolan: Strategier, strukturer och verktyg för att hantera svårigheter och uppnå ett långsiktigt lärande. Malmö: Epago.

Ministry of Integration and Gender Equality. 2000. SOU 2000: 1. En uthållig demokrati!. Demokratiutredningens slutbetänkande. Stockholm: Ministry of Integration and Gender Equality.

Peters, M.A. 2001. Poststructuralism, Marxism and Neoliberalism: Between theory and politics. Lanham, Rowan \& Littlefiedl Publishers, INC.

Prins, E. and B. Willson Toso. 2008. Defining and Measuring Parenting for Educational Success: A Critical Discourse Analysis of the Parent Education Profile. American Educational Research Journal 45: 555-596.

Radulova, E. 2007. The OMC: An opaque method of consideration or deliberative governance in action?. Journal of European Integration 29: 363-380.

Riele, te K. 2006. Youth 'at risk': further marginalizing the marginalized? Journal of Education Policy 21, no. 2: 129-145.

Rose, N. 1996. Governing "advanced” liberal democracies. In Foucault and Political reason: Liberalism, neo-liberalism and rationalities of government, eds. A. Barry, M. Osborne and N. Rose., 37-64. Chicago: The University of Chicago Press.

Rose, N. 1999. Powers of Freedom: Reframing Political Thought. Cambridge: Cambridge University Press.

The Swedish National Agency for Education. 2000. En fördjupad studie om värdegrunden. Stockholm: The Swedish National Agency for Education.

Uljens, M. 2002. The idea of a Universal Theory of Education - an impossible but necessary project? The Journal of Philosophy of Education 36: 353-375.

Walkerdine, V. 1984. Developmental psychology and the child-centred pedagogy: the insertion of Piaget into early education. In Changing the subject: Psychology, social regulation and subjectivity, eds. J. Henriques, W. Hollway, C. Urwin, C. Venn and V. Walkerdine,153-202. London: Methuen.

Wishart, D., A. Taylor, and L. Schultz. 2006. The construction and production of youth 'at risk'. Journal of Education Policy 21, no. 3: 291-304.

Wright Nielsen, T. 2009. Viljen at frigøre. Lund: Department of Social Work, Lund University.

Österlind, E. 1998. Disciplinering via frihet. Uppsala: Department of Eudcation, Uppsala University. 